\title{
Photoluminescence of tetrachloroarsenate(III)
}

\author{
H. Kunkely, V. Pawlowski, A. Vogler \\ Institut für Anorganische Chemie, Universität Regensburg, Universitätsstrasse 31, D-93040 Regensburg, Germany
}

Received 10 June 1994; in final form 4 July 1994

\begin{abstract}
Glasses of $\left(\mathrm{NBu}_{4}\right) \mathrm{AsCl}_{4}$ in ethanol at $77 \mathrm{~K}$ show a red emission at $\lambda_{\max }=617 \mathrm{~nm}$ with $\phi \approx 10^{-4}$ and $\tau=0.46 \mu \mathrm{s}$. It is suggested that this luminescence originates from the sp excited state ${ }^{3} \mathrm{P}_{1}$ of the $\mathrm{As}^{3+}$ ion. The excited state properties of $\mathrm{AsCl}_{4}^{-}$are discussed in comparison to those of $\mathrm{SbCl}_{4}^{-}$and $\mathrm{BiCl}_{4}^{-}$.
\end{abstract}

\section{Introduction}

While Blasse and his group have studied the luminescence of $\mathrm{As}^{3+}$ ions in solid elpasolite, $\mathrm{Cs}_{2} \mathrm{NaScCl}_{6}$ [1], molecular As (III) compounds have not yet been observed to emit according to our knowledge. We explored this possibility and selected the complex anion $\mathrm{AsCl}_{4}^{-}$for the present investigation. This choice was based on our previous study of the emission behavior of the complexes $\mathrm{MCl}_{4}^{-}$and $\mathrm{MCl}_{6}^{3-}$ with $\mathrm{M}=\mathrm{Sb}$ and $\mathrm{Bi}[2,3]$. We expected to see distinct differences in the luminescence properties between the heavy metal complexes $\mathrm{SbCl}_{4}^{-}$and $\mathrm{BiCl}_{4}^{-}$and the corresponding chloro complex of the lighter congener arsenic which as a number of the fourth period of the periodic table is characterized by a smaller spinorbit coupling constant.

\section{Experimental}

The compound $\left(\mathrm{NBu}_{4}\right) \mathrm{AsCl}_{4}$ was prepared according to published procedures [4]. Solutions of this substance were light sensitive. UV irradiation for longer periods led to the deposition of elemental arsenic as a dark brown precipitate. Absorption spectra were measured in solutions of dry acetonitrile under argon at room temperature on a Hewlett Packard 8452A diode array spectrophotometer. Emission spectra were obtained in ethanol glasses at $77 \mathrm{~K}$ on a Hitachi 850 spectrofluorimeter equipped with a $\mathrm{Ha}$ mamatsu 928 photomultiplier. The luminescence spectra were corrected for monochromator and photomultiplier efficiency variations. Luminescence quantum yields were estimated by comparing the integrated emission intensity of $\left(\mathrm{NBu}_{4}\right) \mathrm{AsCl}_{4}$ in an ethanol glass with that of europium thenoyltrifluoroacetonate $\left(\lambda_{\max }=612 \mathrm{~nm}, \phi=0.56\right)$ under comparable conditions. Emission lifetimes were measured on a luminescence analysis system (model LS100-07) from Photon Technology International.

\section{Results}

The absorption spectrum of $\mathrm{AsCl}_{4}^{-}$in acetonitrile (Fig. 1) shows a weak band at $\lambda_{\max }=359 \mathrm{~nm}(\epsilon=12.3$ $\mathrm{M}^{-1} \mathrm{~cm}^{-1}$ ) and an increase of the extinction towards shorter wavelength. Weak shoulders appear around 310 and $270 \mathrm{~nm}$. While at room temperature $\mathrm{AsCl}_{4}^{-}$was not emissive, a red photoluminescence at $\lambda_{\max }=617 \mathrm{~nm}$ was observed in ethanol glasses at 77 


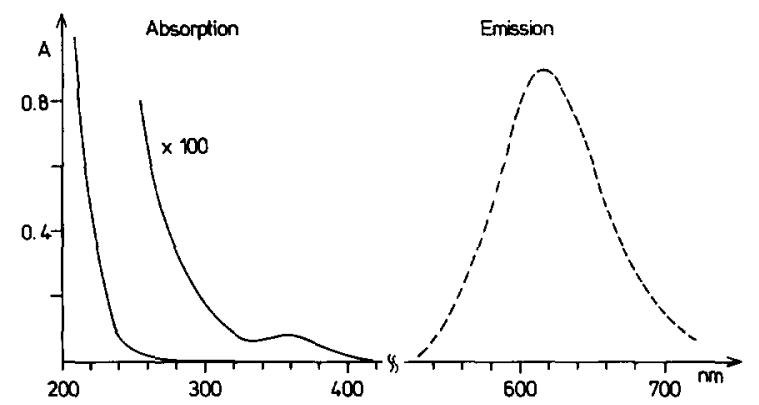

Fig. 1. Electronic absorption (-) and emission (---) spectra of $\left(\mathrm{NBu}_{4}\right) \mathrm{AsCl}_{4}$. Absorption: $9.20 \times 10^{-5} \mathrm{M}$ in acetonitrile under argon at room temperature, $1 \mathrm{~cm}$ cell. Emission: $10^{-2} \mathrm{M}$ in ethanol at $77 \mathrm{~K}, \lambda_{\text {exc }}=300 \mathrm{~nm}$, intensity in arbitrary units.

K (Fig. 1). The excitation spectrum was quite featureless but agreed qualitatively with the absorption spectrum. The emission quantum yield was roughly $\phi=10^{-4}$ at $\lambda_{\text {exc }}=300 \mathrm{~nm}$. The emission decayed with a lifetime of $\tau=0.46 \pm 0.03 \mu \mathrm{s}$.

\section{Discussion}

In analogy to $\mathrm{SbCl}_{4}^{-}$and $\mathrm{BiCl}_{4}^{-}[2,3]$ the longwavelength absorptions of $\mathrm{AsCl}_{4}^{-}$are assigned to sp transitions of the central $\mathrm{s}^{2}$ ion. The $\mathrm{A}$ band $\left({ }^{1} \mathrm{~S}_{0} \rightarrow{ }^{3} \mathrm{P}_{1}\right.$ transition ) of $\mathrm{AsCl}_{4}^{-}$at $\lambda_{\max }=359 \mathrm{~nm}$ is much weaker than those of $\mathrm{SbCl}_{4}^{-}$and $\mathrm{BiCl}_{4}^{-}$since the spin-selection rule is largely valid for arsenic which belongs to the fourth period of the periodic table. In contrast, the spin-forbidden transitions of $\mathrm{SbCl}_{4}^{-}$and $\mathrm{BiCl}_{4}^{-}$ become partially allowed by strong spin-orbit coupling of the heavier metals antimony and bismuth. The B $\left(\lambda_{\max } \approx 310 \mathrm{~nm}\right)$ and $C\left(\lambda_{\max } \approx 270 \mathrm{~nm}\right)$ bands of $\mathrm{AsCl}_{4}^{-}$which are assigned to the ${ }^{1} \mathrm{~S}_{0} \rightarrow{ }^{3} \mathrm{P}_{2}$ and ${ }^{1} S_{0} \rightarrow{ }^{1} P_{1}$ sp transitions, respectively, are obscured by another absorption which increases in intensity towards shorter wavelength. We assign this band to a ligand-to-metal charge transfer (LMCT) transition which involves the promotion of a chloride electron to the $p$ orbitals of As (III). Analogous LMCT bands were also identified in the absorption spectra of halide complexes of other $s^{2}$ ions $[3,5]$. In the case of $\mathrm{AsCl}_{4}^{-}$the LMCT assignment is supported by the observation that $\mathrm{UV}$ irradiation of $\mathrm{AsCl}_{4}^{-}$in $\mathrm{CH}_{3} \mathrm{CN}$ leads to a photoredox decomposition with the formation of elemental arsenic. The sp absorptions of
$\mathrm{As}^{3+}$ in $\mathrm{Cs}_{2} \mathrm{NaScCl}_{6}$ matrix appear at shorter wavelengths ( $A$ band at $\lambda_{\max }=308 \mathrm{~nm}, B$ band at $281 \mathrm{~nm}$, $C$ band at $250 \mathrm{~nm}$ ) [1] than the corresponding absorptions of $\mathrm{AsCl}_{4}^{-}$.

In analogy to many other chloride complexes of $\mathrm{s}^{2}$ ions [3] the emission of $\mathrm{AsCl}_{4}^{-}$at $\lambda_{\max }=617 \mathrm{~nm}$ is assigned to the ${ }^{3} \mathrm{P}_{1} \rightarrow{ }^{1} \mathrm{~S}_{0}$ transition. Its spin-forbidden character is in accordance with the observation that this emission appears only at low temperatures while the luminescence of $\mathrm{SbCl}_{4}^{-}$and $\mathrm{BiCl}_{4}^{-}$can be clearly seen in solution at room temperature $[2,3]$. A rough estimate of the radiative lifetime of $\mathrm{AsCl}_{4}^{-}$ based on the emission quantum yield $\left(\phi \approx 10^{-4}\right)$ and lifetime $(\tau=0.46 \mu \mathrm{s})$ yields a reasonable value of approximately $10 \mathrm{~ms}$ which compares with $2.5 \mathrm{~ms}$ for $\mathrm{As}^{3+}$ in $\mathrm{Cs}_{2} \mathrm{NaScCl}_{6}$.

The Stokes shift of the ${ }^{1} \mathrm{~S}_{0} \leftrightarrow{ }^{3} \mathrm{P}_{1}$ transition of $\mathrm{AsCl}_{4}^{-}$amounts to $11650 \mathrm{~cm}^{-1}$. Stokes shifts of this magnitude were also observed for $\mathrm{SbCl}_{4}^{-}$and $\mathrm{BiCl}_{4}^{-}$. It is suggested that this shift is caused by a structural change from disphenoidal $\left(C_{2 v}\right)[6]$ in the ground state toward a tetrahedral geometry in the ${ }^{3} \mathrm{P}_{1}$ excited state $[2,3]$. It is quite interesting that the Stokes shift of $\mathrm{AsCl}_{4}^{-}$is comparable to that of $\mathrm{As}^{3+}$ in $\mathrm{Cs}_{2} \mathrm{NaScCl}_{6}$ $\left(\Delta \bar{\nu}=12200 \mathrm{~cm}^{-1}\right)[1]$. It was assumed that in the latter case the large shift is related to the fact that $\mathrm{As}^{3+}$ ions which occupy octahedral sites in the halide matrix are rather small. In the ground state they may thus not be located in the center of octahedral sites formed by the chloride ions. Accordingly, the effective coordination number for $\mathrm{As}^{3+}$ in $\mathrm{Cs}_{2} \mathrm{NaScCl}_{6}$ might be smaller than 6, possibly 4 as for $\mathrm{AsCl}_{4}^{-}$.

As an alternative, the long radiative lifetime of $\mathrm{AsCl}_{4}^{-}$may have a different origin. Generally, the lowest energy sp transition which takes place between the ${ }^{1} S_{0}$ ground state and the ${ }^{3} P_{0}$ state is not seen in either absorption or emission since it is strongly forbidden [7]. If in the case of $\mathrm{AsCl}_{4}^{-}$the ${ }^{3} \mathrm{P}_{0}$ state is somehow populated its radiative deactivation should be extremely slow in accordance with our observation. It follows that the Stokes shift of this emission is then smaller than that noted above for the ${ }^{1} \mathrm{~S}_{0} /{ }^{3} \mathrm{P}_{1}$ transition because the undetected ${ }^{1} \mathrm{~S}_{0} \rightarrow{ }^{3} \mathrm{P}_{0}$ absorption should be located at lower energy than the ${ }^{1} \mathrm{~S}_{0} \rightarrow{ }^{3} \mathrm{P}_{1}$ absorption. 


\section{Acknowledgement}

Support of this research by the BMFT and the Fonds der Chemischen Industrie is gratefully acknowledged. We are grateful to Professor C.K. Jørgensen for helpful comments.

\section{References}

[1] E.W.J.L. Oomen, W.M.A. Smit and G. Blasse, Chem. Phys. Letters 138 (1987) 584.
[2] H. Nikol and A. Vogler, J. Am. Chem. Soc. 113 (1991) 8988.

[3] A. Vogler and H. Nikol, Comments Inorg. Chem. 14 (1993) 245.

[4] G. Brauer, Handbuch der präp. anorg. Chemie (Enke Verlag, Stuttgart, 1975) p. 573.

[5] K. Oldenburg and A. Vogler, Z. Naturforsch. 48b (1993) 1519.

[6] G.Y. Ahlijah and M. Goldstein, J. Chem. Soc. (A) (1970) $326,2590$.

[7] G. Blasse, Rev. Inorg. Chem. 5 (1983) 319; Progr. Solid State Chem. 18 (1988) 79. 